\title{
SFU Academic Summer Camp for Aboriginal Students 2014 - 2018
}

\author{
Veselin Jungic ${ }^{1}$ and Sheryl Thompson ${ }^{2}$ \\ ${ }^{1}$ Department of Mathematics and ${ }^{2}$ Faculty of Health Sciences, Simon Fraser University, Burnaby, British Columbia, Canada
}

Keywords: Aboriginal, Summer Camp, High School, Science Outreach

Publication Date: April 29, 2020

DOI: https://doi.org/10.15695/jstem/v3i1.04

\begin{abstract}
The purpose of this note is to summarize and share with the wider academic and non-academic communities our experience over five years, 2014 - 2018, running the Simon Fraser University Academic Summer Camp for Aboriginal High School Students. In what follows we describe our reasons for developing this outreach activity and provide the goals and objectives of this initiative. To reach out to those members of the community who are planning or already running similar outreach activities, we also provide details about the camp components, including staffing, budgeting, recruiting, and scheduling. In addition, we highlight testimonials by students, parents, and teachers.
\end{abstract}

\section{INTRODUCTION}

The existence of a general education gap between Indigenous and non-Indigenous populations in Canada is well documented (Pidgeon, 2008; Ottmann, 2017). In 2016, for example, $10.9 \%$ of the Indigenous population between 25 and 64 years of age had a bachelor's degree or higher in comparison to $28.5 \%$ of the general Canadian population of the same age rang (Statistics Canada, 2017). Considering that the Indigenous population makes up about $5 \%$ of the total Canadian population, that means that among all Canadians between 25 to 64 with a bachelor's degree or higher, only about $2 \%$ are Indigenous.

Canadian universities, particularly in the light of the Truth and Reconciliation Commission's 94 Calls to Action (Truth and Reconciliation Commission of Canada, 2015), have committed significant resources to recruiting and retaining Indigenous students, hiring Indigenous academics, and, in general, establishing meaningful collaboration with the local Indigenous communities. The authors of this note, and particularly the second author, an Indigenous graduate student herself, have witnessed and been involved in multiple initiatives and conversations at our institution, Simon Fraser University (SFU), which aimed at addressing the above-mentioned education gap (Reconciliation at SFU, 2020).

The degree of complexity of the historical, cultural, economic, and political issues related to the education of Indigenous youth in Canada is such that it will take time, patience, and joint efforts of all involved, Indigenous and academic communities, individual students, instructors, and administrators to change the existing reality. And that reality is such that, for example, in 2019 among about 30,000 SFU under- graduate students there were about 600 Indigenous students (Institutional Research and Planning, 2020a). Thus, Indigenous students comprise about $2 \%$ of the SFU undergraduate population, which mirrors our estimate of the ratio of the Indigenous population among Canadians with a bachelor's degree or higher.

It should be mentioned that other societies with histories of colonization are going through their own processes of reconciliation. These processes include addressing the education gap between Indigenous and non-Indigenous populations. For an extensive account of mostly Australian experiences see (Frawley et al., 2017). For an excellent summary of the current state of Māori (New Zealand) higher education see (Theodore et al., 2016).

Still, we agree with Ottmann (2017) that "there are encouraging signs on the horizon" (p. 114). The layered complexity of issues related to the education of Indigenous learners resembles what mathematicians call fractals: "infinitely complex patterns that are self-similar across different scales" (Fractal Foundation, 2020). In our many interactions with individual Indigenous students, Indigenous families, Indigenous schools, and broader Indigenous communities we have commonly encountered eagerness, curiosity, and capacity to gain and share knowledge and experiences. At the same time, it seems that the long shadows cast by the legacy of 150 years of history of residential schools are ever-present through the fact "that Aboriginal people still have lower educational and economic achievements than other Canadians" (Truth and Reconciliation Commission of Canada, 2015, p. 62). 
This fractal nature of opportunities and challenges related to the education of Indigenous learners determined our approach of encouraging Indigenous high school students to choose a STEM field of study: our vision was to run an outreach program that would build a tight community of learners by supporting one student at the time.

STEM outreach activities for Indigenous youth, including summer camps, have been held in various formats across the globe. Here are only a few examples: "Bridging cultures: Mapping your destination with science, mathematics and technology," a summer camp at the University of Lethbridge, Lethbridge, AB, Canada (Hogue, 2016), "STEM spring workshop" at the University of Sydney, Sydney, NWT, Australia (Phillips and Ly, 2020), "He Puna Pūtaiao" a programme at the University of Canterbury, New Zealand (University of Canterbury, 2020), and "The Alliance of Indigenous Math Circles" across the United States of America (Klein and Shubin, 2019).

\section{The SFU Academic Summer Camp: What, Why, and How}

The Simon Fraser University Academic Summer Camp for Aboriginal High School Students ("the camp" in the rest of the text) sought to address the under-representation of Indigenous peoples in Canadian Universities, particularly in science and engineering programs. For example, in 2018, Indigenous students enrolled in the SFU Faculty of Applied Science programs, i.e., enrolled in one of the engineering or computer science programs, made up only about $0.9 \%$ of the student population. In the SFU Faculty of Science this number was about 1.5\% (Institutional Research and Planning, 2020b).

The main purpose of the camp was to strengthen academic engagement and cultural awareness among First Nations, Metis, and Inuit (FNMI) students who attended, regardless of their high school grades. This was an important decision as it manifested our commitment to meeting youth wherever they were in their learning journeys.

The camp operated as a day-camp, from $9 \mathrm{am}-4 \mathrm{pm}$, Monday-Friday, over four weeks in July. The camp participants, a group of about two dozen self-identified FNMI high school students, attended math and English classes and participated in workshops on topics including chemistry, statistics, physics, biology, earth science, engineering, and computing science. Camp participants were also involved in numerous activities relating to Indigenous cultures and traditions. In summary, each camp participant was engaged in approximately 30 hours of mathematics and 30 hours of English classes, 24 hours of STEM experience, 10 hours of cultural activities, 8 hours of physical activities, and 8 hours of other activities including career planning, interacting with guest speakers, attending public speaking workshops, and team building activities.

The structure of our program was strongly influenced by what Pidgeon and colleagues call "a wholistic Indigenous framework" (2014, p.7). We note that "the spelling of "wholistic" with a " $w$ " is intentional and reflects the interconnections and interrelationships that are important components of Indigenous epistemologies" (Pidgeon et al., 2014, p.14). The camp was built on the expectation that all involved, students, their families, teachers, volunteers, guest presenters, and the camp staff, would:

- show respect for themselves and each other, and also respect other SFU students and staff and the SFU property;

- create positive relationships among each other, within the whole group, and within the wider SFU community;

- take responsibility for their own main roles in the camp: students for their own learning; teachers, volunteers, and the guest presenters for meeting each participant's learning needs; staff for ensuring that everything ran smoothly; and families for supporting students, teachers and staff to the best of their abilities;

- emphasize the relevance of the camp activities to the past, present and the future of the Indigenous communities and their individual members as part of the ongoing reconciliation process.

In addition, and in the accordance with a wholistic Indigenous framework, all activities were created with the purpose to provide multiple opportunities for the participants' individual intellectual, physical, emotional, and spiritual (cultural) growth.

By introducing participants to the life of a university student, the camp promoted the idea of post-secondary education as something that was interesting, useful, and achievable for Indigenous students. The teaching philosophy of the camp was based on two principles: (1) each participant received the full attention of all teachers and staff; and (2) a strong community of learners was built through the use of a cohort model and a variety of cooperative activities.

Based on students' and parents and guardians' testimonials, our approach of treating students with care and respect while challenging them academically helped them to improve their math, English, and general learning skills.

This brings us to one of the main questions that we faced throughout the five years of running the camp: "How do you measure the success of the camp?" What our undoubtedly well-meaning colleagues, both on the instruction and administration sides, meant by "success" was that the completion of the program would be "a social marker of success that leads to upward career advancement and higher socio-economic status" (Pidgeon, 2008, p. 340).

As we have already mentioned, the complex issue of education of Indigenous youth in Canada is deeply rooted in over 
150 years of colonization and mistreatment of the Indigenous population. Hence, it would be unrealistic to expect that by attending a month-long event each camp participant would find the answers to all of their learning and other educational needs. This was the reason that we promoted and ran the camp as an outreach program rather than a university bridging program.

Our understanding of "success" was closer to what Pidgeon describes as "counter-hegemonic points-of-view of educational success" that "do not devalue the economic and social benefits of higher education but do challenge the limited boundaries of what it means to be successful" (2008, p. 340). For example, we received testimonials from the former Camp participants that the camp was a life changing experience for them. Those changes ranged from a parent's genuine surprise that her son was eager to go to school during a summer month to acknowledging the newly discovered self confidence in their math skills to re-connecting with their Indigenous cultural background to deciding to apply for a university admission.

Possibly the proudest achievement for the camp organizers and staff was that, regardless of the fact that the group of participants was very diverse, all students accepted over five years to the camp completed the program. It was particularly rewarding to witness how quickly the camp participants were able to form a tightly connected group of committed learners.

In a way, the reason for this success was simple: a well-treated group of young learners supported by a caring staff both on an individual and group levels, in an intellectually and culturally stimulating environment, thrived and stayed together. Similar observations in the context of Indigenous undergraduate students were made by Gallop and Bastien (2016).

\section{THE MODEL}

The Camp originated as a joint initiative of the "Emerging Aboriginal Scholars Summer Camp" run by the Pacific Institute for Mathematical Sciences (PIMS) in partnership with the University of British Columbia (UBC) First Nations House of Learning (Alvarez, 2019) and the SFU Math Catcher Outreach Program. (Archibald and Jungic, 2016; Math Catcher Outreach Program, 2020a).

Since the camp was built on the established UBC-PIMS model, the two camps had the same format, math and English classes every morning, a strong cultural component throughout the duration of the camp, and daily interactions between the camp participants and the members of the host academic community.

The major difference was in the way the above-mentioned interaction was organized. One of the "Emerging Aboriginal Scholars Summer Camp" objectives was described as:

To expose aboriginal students to real life work experience with faculty and other members of the university community while working on a field of their choice.
Expose students to research and employment possibilities in a variety of professions. A hands-on working experience in a setting which encourages excellence. (PIMS, 2020)

In practice, this meant that individual camp participants were invited to join a UBC research group or a lab and do appropriate work under the supervision of a faculty member. The camp participants were paid at an hourly rate for this work. The SFU camp aimed to strengthen community connections among the camp participants by exposing them as a group of learners to various academic and non-academic events: guest lectures, workshops, hands-on activities, field trips, and organized recreational exercises. In what follows we describe the camp model by giving the details of its various components, including staffing, budgeting, recruiting, and scheduling.

Students. The table below summarizes basic statistics about the students enrolled in the Camp in the period 2014-2018. Camp participants came from families of different economic backgrounds, which ranged from those struggling to maintain housing while attending class to comfortable upper middle-class incomes. The students' homelife varied from traditional communal living, nuclear two-parent households, alone living with relatives, part of the Ministry of Children and Family's care, and many variations in between. There were also great differences in the family support students received to attend camp, from being driven each day by a parent/guardian to getting themselves up in time to transit nearly two hours to arrive to campus on time. The students came from all over the Greater Vancouver area as well as other BC communities. For example, in 2016 camp participants came from ten $\mathrm{BC}$ communities. In the same year, the students self-identified as members of 18 Nations.

The academic background of the camp participants also varied greatly, from students who needed to improve their basic numeracy and literacy skills to students who had already completed mathematics courses above their grade level. Some students faced learning and health challenges. Those ranged from dyslexia to mild mental disorders to physical disabilities. During the selection process, the camp organizers made it clear to students and their parents and

Table 1. The population of the camp participants represented a cross section of the urban Indigenous community in the Greater Vancouver area.

\begin{tabular}{ccccc}
\hline \multicolumn{5}{c}{ Academic Summer Camp for Aboriginal - Students } \\
\hline & \# of students & Grades 8-9 & Grades 10-11 & Gender F/M \\
\hline 2014 & 25 & & $16 / 9$ & \\
2015 & 26 & 9 & 17 & $14 / 12$ \\
2016 & 26 & 7 & 19 & $16 / 10$ \\
2017 & 26 & 15 & 11 & $16 / 10$ \\
2018 & 21 & 12 & 9 & $12 / 9$ \\
\hline
\end{tabular}


guardians that the camp could not offer any specialized accommodation to students with disabilities.

In practice, things were quite complex. For example, one of the challenges was building trust between the students and the staff; i.e., finding a balance between communicating and imposing strict rules of students' conduct (attendance and timeliness, the level of engagement in the camp activities, behavior inside and outside of the classroom) and leaving enough room for often strong characters to fully accept and implement the rules at their own pace.

\section{My time at the SFU summer math and English camp was a summer I will always remember. Throughout the camp I had met amazing teachers and students who I still talk to, to this day. I know that the experienc- es I had there had allowed me to be more open with myself and gave me a platform to let go of what had been holding me back. I would say this camp had a positive influence on a lot of the things I decided to do after the summer of 2014. I remember always be- ing excited for English and Math during the camp, not only did the teachers make it easier to learn but they made learning so much fun. Although I have to say I loved English a little more, our teacher that year was and continues to be a huge inspiration for me. - Camp participant}

Building cohesion within the cohort was essential for camp success (Gallop and Bastien, 2016). Creating a community that was invested in the success of each of its members helped to develop a caring and respectful environment where students wanted to come and learn. Ensuring everyone had one or two buddies with whom they could spend breaks made students feel important and needed, whether as isolated outsiders now part of a group or as leaders who had taken concrete action to include someone in a wider community. Facilitating large group activities such as voice lessons stretched students' comfort zones in very safe and protective ways and also helped to build a sense of solidarity and trust among the camp participants.

Staff. The number of core-staff involved in organizing and running the annual camp varied between five and eight over the years. See Table 2 for duties. A key staff person was the Camp Coordinator who acted as the primary point of contact for the youth, teachers, other staff, volunteers, and guest speakers. Over the course of five years, the Camp Coordinator was the same person, Ms. Sheryl Thompson, a co-author of this note, a very successful mature Indigenous, at that time, undergraduate SFU student herself: a knowledgeable "Auntie" figure with extensive experience with youth and familiar with the university and its services. Her capacity to act as a role model learner as well as a caring adult greatly contributed to the fact that all camp participants completed the program.

My son comes home every day with news of the camp. At first it was about the people he was meeting and getting to know. Then it was a new math question every day, that he would explain to all of us. The Friday that he had to miss he asked a friend to send him any new math questions. I have to say that he has enjoyed most outing but by far the "battery" trip has taken the lead. He was very animated that night and said he asked a lot of questions while there. He also sings the praises of both the math and English teachers. He has always liked math but for him to enjoy English is really something. - Parent of camp participant

A common attribute among all teachers involved in the camp was their ability to establish a learning environment where each student would get the opportunity to demonstrate their skills, develop and explore their talents, and meet their individual learning needs. This was not an easy task. It required teachers' full commitment to the program, endless patience, and a lot of work in- and out-of-classroom. For example, the math teacher regularly provided content-specific tasks for each individual student. This way, each student, with the teacher's support and the help of volunteer tutors, worked at his or her own pace on the most appropriate set of math questions. The English teacher's goal was to encourage the camp participants to further develop their writing and critical thinking skills through addressing issues related to students' personal, social, and cultural experiences.

Having the opportunity to experience this year's group has been wonderful. Since its inception in 2007 I've watched this program grow, thrive and evolve into what it is today. Indeed, I love teaching mathematics, but working with these kids is incredibly rewarding, as they help make me a better teacher and listener, giving me something to bring to my classroom in September. Time and again I have to come to grips with the fact that these kids are giving up half their summer to improve their math and English skills, while the sun shines outside. Their eagerness to learn is admirable. - Camp math teacher

The success the camp experienced over the years was due in large part to the commitment and support of the staff from various SFU units: Indigenous Student Centre, Office for Aboriginal Peoples (OAP), First Nation Student Association, the Department of Mathematics, the Faculty of Science, the Faculty of Applied Science, the IRMACS Centre, the Recreation Department, the Teaching and Learning Centre, the Learning Commons, and Food Services and Facilities, for example. 
Table 2. Academic Summer Camp staff roles and duties

\begin{tabular}{|c|c|c|c|c|}
\hline \multicolumn{5}{|c|}{ Academic Summer Camp for Aboriginal Students - Staffing } \\
\hline Position & Duties & Employment & Period & Notes \\
\hline Director & $\begin{array}{l}\text { Overall responsibility and coordination of the SFU in-kind support } \\
\text { amp; advertising; recruiting students, staff, guest peakers, and } \\
\text { volunteers; managing the application and selection processes; } \\
\text { funding and budgeting; cheduling; media }\end{array}$ & SFU Faculty & 2014-2018 & SFU in-kind support \\
\hline Manager & $\begin{array}{l}\text { Application and acceptance form development; supervision of } \\
\text { staff; budgeting; scheduling; general advice }\end{array}$ & SFU Staff & 2014-2016 & IRMACS in-kind support \\
\hline Advisor & $\begin{array}{l}\text { Advertising; recruiting students and volunteers; help with manag- } \\
\text { ing the application and selection processes; general advice }\end{array}$ & PIMS Staff & $2014-2018$ & PIMS in-kind support \\
\hline Coordinator I & $\begin{array}{l}\text { Day-to-day management of the camp; students' supervision } \\
\text { including taking attendance and timely dealing with discipline/ } \\
\text { behavior issues; main contact person for students and parents and } \\
\text { guardians; main contact for other staff members; main contact } \\
\text { for ISC; main coordinator of the cultural activities; day-to-day } \\
\text { purchasing (food, supplies); preparation and coordination of the } \\
\text { closing day; documenting the camp events (photos and weekly } \\
\text { summaries) }\end{array}$ & Contract & 2014-2016 & 1 month - FT \\
\hline Coordinator II & $\begin{array}{l}\text { Coordinator I duties plus: selection process; camp preparation in- } \\
\text { cluding contacting students their parents and guardians, providing } \\
\text { Assistant II with lists of supplies and other necessary information, } \\
\text { and assisting Director in inspecting and choosing potential camp } \\
\text { facilities }\end{array}$ & Contract & $2017-2018$ & $\begin{array}{l}2 \text { months }(1-\text { month PT, } \\
1 \text {-month FT) }\end{array}$ \\
\hline Math teacher & $\begin{array}{l}\text { Math assessment; developing and delivering math content; mark- } \\
\text { ing assignments; directing and managing volunteer tutors }\end{array}$ & Contract & 2014-2018 & 1-month FT \\
\hline English teacher & Developing and delivering English course content & Contract & 2014-2018 & 1-month FT \\
\hline $\begin{array}{l}\text { Directed Studies } \\
\text { teacher }\end{array}$ & Delivering a high school for credit course & Contract & 2014-2015 & 1-month PT \\
\hline Financial clerk & Payroll; managing day-to-day transactions; budget reporting & SFU Staff & 2014-2016 & IRMACS in-kind support \\
\hline $\begin{array}{l}\text { Administrative } \\
\text { Assistant I }\end{array}$ & $\begin{array}{l}\text { Creating various spreadsheets; all bookings; ordering of supplies; } \\
\text { creating students' folders; general assistance to the camp coordi- } \\
\text { nator before and during the camp }\end{array}$ & SFU Staff & 2014-2016 & IRMACS in-kind support \\
\hline $\begin{array}{l}\text { Administrative } \\
\text { Assistant II }\end{array}$ & $\begin{array}{l}\text { Payroll; managing day-to-day transactions; budget reporting; } \\
\text { development and maintenance of the online application process; } \\
\text { Creating various spreadsheets; website development and updates; } \\
\text { all bookings; ordering of supplies }\end{array}$ & SFU Staff & $2017-2018$ & $\begin{array}{l}\text { Department of Mathematics } \\
\text { in-kind support }\end{array}$ \\
\hline $\begin{array}{l}\text { Coordinator's } \\
\text { Assistant }\end{array}$ & General assistance to the camp coordinator & Contract & $2017-2018$ & 1-month FT \\
\hline Technical Support & Website development and support & SFU Staff & 2014-2016 & IRMACS in-kind support \\
\hline
\end{tabular}

Volunteers. Each year, a group of SFU students volunteered to tutor the camp participants one-on-one during the math classes. The volunteers came mostly from the Faculty of Education and the Department of Mathematics. The number of volunteer tutors varied between five and eight per year. Members of the SFU First Nation Student Association volunteered their time and experience during the cultural activities, mealtimes, and on fieldtrips.

My daughter became very motivated to attend university after doing the first SFU Academic camp. Attending this camp has made her believe it even more as she is closer to graduating now. She spoke at length about the Indigenous Student Centre at SFU that offers career counselling, student loan assistance and other services to help you while at University. I think this was a huge, helpful piece of information that made her feel less fearful and more confident as she felt there would be somewhere to go for help in all aspects of university life, someone that would care and want to help. Hearing that other people have had obstacles like tragedy or family issues and have overcome them and went on to University is also very motivating for her. I know she worries about how her education will be paid for as we have been honest with her that we will only be able to pay for a small portion and that she will have to apply for scholarships and student loans. The camp has made her see that not everyone has their education paid for, nor do they all have easy lives and even so they find a way, work hard and achieve their goals. - Parent of camp participant 
Guest Speakers. Each year, a group of guests that included SFU faculty and staff, academics from other institutions, elders, Indigenous students, and members of various Indigenous communities met with the camp participants. The guest lectures and workshops can be roughly categorized in the following, possibly overlapping, categories:

- Cultural workshops, such as when an elder from the Tla'amin Nation gave a workshop about the relationship between the traditional Tla' amin basketry and mathematics.

- Hands-on Cultural workshops, such as weaving bulrush reeds, drum making, and medicine pouch teachings.

- STEM workshops; for example, over the years the most popular guest speaker was a prominent SFU criminology professor and forensic entomologist who spoke about the science behind crime scene investigations; or walks around Burnaby Mountain led by a leading Canadian geologist.

- Hands-on STEM activities; for example, each year, the SFU Faculty of Applied Sciences organized a robot building workshop; or members of the Department of Chemistry taught everything from making liquid nitrogen ice cream to lining a test tube with silver; or hands-on workshops led by mathematicians from and outside of SFU.

Each student successfully completed and tested the LED circuit project within the given time. They all presented as enthusiastic, polite, bright folks. On average, they demonstrated above average hand-skill abilities. Most, when asked (male or female), already had a fairly broad intro to many practical skills in school (many skills that the bulk of our regular students don't seem to have or weren't offered). - STEM workshop moderator

- Skill development; for example, camp participants were involved in workshops that taught them public speaking and expression skills, navigating various public spaces, and self-advocacy.

- Role models; students met a number of Indigenous professionals, including a nurse, an accountant, a teacher, and a provincial level administrator; Indigenous artists, including a film director, a poet, a painter, and a sculptor; and Indigenous community leaders, including elders, administrators, knowledge keepers, and SFU staff and faculty

- Art; for example, an award-winning artist from the United Kingdom introduced a particular painting technique to the camp participants.
In general, our guest speakers gave their workshops and presentations at no charge. For speakers outside the Greater Vancouver Area, the camp covered their travel expenses. It was the camp's policy to pay a modest honorarium to elders and Indigenous artists for their time.

The interaction with the teachers and especially the students helped influence me in a great way. I was pretty reserved in my first year of high school and also during the summer camp (until the last day) but some of the words my fellow students said stuck with me and I used it as my words to go by when $i$ would go into my second year of high school. The phrases that were said to me is "be open with yourself" "you are a interesting person" which gave me a new self-confidence which allowed me to have an enjoyable school year in the school year of 2015/2016. Since completing the camp, I am deciding to focus on getting into computer science, so I have focused on my math classes and have taken a computer programming course and hopefully to get another for my final year. - Camp participant

Budget. Over the first four years, the camp was financed from three sources: Natural Sciences and Engineering Research Council of Canada (NSERC) Promo Science program, SFU, and PIMS. About the same amount of funds were provided in cash and in-kind support. About two-thirds of the cash funds were needed to cover the staff salaries and the student honoraria. Similarly, the salaries of the SFU and PIMS faculty and staff made up the large portion of the total in-kind contributions. Knowing how much work over several months was needed to organize and run the camp and the commercial pricing of renting the university space, it is easily possible that the real value of the in-kind contributions exceeded the committed amount. Table 3 contains a typical annual budget for the Camp between 2014-2017.

In the fifth year, through a combination of a generous donation, reduced cash contributions from SFU and PIMS, and some funding saved over the years the costs were covered. The university and PIMS in-kind contributions stayed about the same as during the previous years.

\section{Practical Matters.}

Recruiting. Recruitment was done mostly through the established channels of PIMS, OAP, and the Math Catcher Outreach Program. The main contacts were Aboriginal support/resource teachers in the public-school system and teachers and administrators from schools in Indigenous communities. The fact that Camp organizers already had established relationships of mutual trust and respect with a large group of teachers that work with Indigenous youth on a daily basis cannot be overestimated or easily measured. In our experience, and particularly when reaching out to the 
Table 3. Typical Camp budget between 2014-2017. "Various academic and non-academic units. ${ }^{* *}$ Including Opening Day and Closing Day receptions. ${ }^{* * *}$ Including monthly transit pass for each student.

\begin{tabular}{|c|c|c|c|c|c|}
\hline \multicolumn{6}{|c|}{ Academic Summer Camp for Aboriginal Students - Budget } \\
\hline \multicolumn{3}{|c|}{ Income } & \multicolumn{3}{|c|}{ Expenses } \\
\hline Source & Cash & In-Kind & Cas & & In-Kind \\
\hline NSERC & $\$ 21,000$ & - & Food $^{* *}$ & $\$ 7,500$ & \multirow{6}{*}{$\begin{array}{l}\text { Salaries } \\
\text { for SFU } \\
\text { and PIMS } \\
\text { employees, } \\
\text { space, IT } \\
\text { support, } \\
\text { copying }\end{array}$} \\
\hline University* $^{*}$ & $\$ 11,000$ & $\$ 25,000$ & $\begin{array}{l}\text { Student } \\
\text { Honoraria }\end{array}$ & $\$ 10,000$ & \\
\hline PIMS & $\$ 10,000$ & $\$ 20,000$ & Salaries & $\$ 16,000$ & \\
\hline \multirow[t]{3}{*}{ Total } & \multirow[t]{3}{*}{$\$ 42,000$} & \multirow[t]{3}{*}{$\$ 45,000$} & Supplies ${ }^{* * *}$ & $\$ 6,000$ & \\
\hline & & & Field Trip & $\$ 1,000$ & \\
\hline & & & $\begin{array}{l}\text { Honoraria } \\
\text { and Travel } \\
\text { Expenses }\end{array}$ & $\$ 1,500$ & \\
\hline
\end{tabular}

urban Indigenous student population, those teachers were a key element in the recruiting process. Their recommendation was an assurance to the students and their parents/guardians that the camp program would be safe, meaningful, culturally sensitive, and academically beneficial for its participants.

The media and a web presence, as well as positive word of mouth helped further promote the camp. As a consequence, in the later years the organizers were directly contacted by interested students, parents and guardians, social workers, and government and non-government agencies that worked with the Indigenous youth.

Application Process. Typically, the application process was open between early March and late April. During the first three years, an application form was sent out as part of a call for applications. The form had three parts, a general information about the camp, the applicant's personal information, and the "Camp Participant Expectation Agreement" (Math Catcher Outreach Program, 2020b). The applicants were asked to fax, mail, or e-mail the completed and signed forms.

In 2017 and 2018, an online application process was created. As part of the application evolutionary process, beginning in year three, the applicants were asked to include a 500-word essay on the topic: "Issues that are important to me." This essay was added to allow the applicants to demonstrate a commitment to participating and to reduce the number of applications which sought to use the camp as a supervision tool for uninterested and uncooperative participants.

Selection. During the first two weeks of May, the selection committee reviewed the applications including the submitted essays. The composition of the selection committee varied over the years, depending on people's availability and the changes that the camp itself was going through. In any year, the committee was a subset of this group of people: Director, Manager, Camp Coordinator, and the PIMS representative. An English teacher was also invited to read the essays and send her feedback to the committee.
Great care was taken to select a diverse group of Indigenous youth to create a rich and dynamic learning cohort. This included trying to find the gender and the school grade related balances in the future cohort. Beginning in the second year, 3-5 campers from previous years were selected to return as 'senior' campers.

In general, the committee looked for complete applications with applicant's clear commitment that they would fully participate in all camp activities. The request for a written essay significantly reduced the number of applications, from about 100 in 2015 to about 40 for each of the following years. This greatly simplified the selection process. Some of the applications were incomplete and a few of the accepted applicants declined our offer to join the camp. It was our experience that a pool of about 40 applicants would lead to about 25 fully committed camp participants.

In mid-May a letter of acceptance was sent to the selected applicants copied to their parents/guardians and teachers, when appropriate. The acceptance letter included a request that the accepted students and their parents/guardians complete, sign, and return/submit several additional forms. Those forms included Camp Participant Expectations, Medical Emergency Information, Assumption of Risk, and Media Release.

Scheduling. To respect the social, individual, and learning needs of the camp participants, developing a daily schedule required balancing scholastic, nutrition, self-reflection, and community connectivity needs. A typical week followed the schedule is displayed on Table 4 . There were a few regular occurrences when this format was not followed: on the opening and closing days, and on the field trip day to the Museum of Anthropology and TRIUMF, Canada's particle accelerator centre.

Physical activities, nutritious meals and snacks, and social gathering times punctuated the day and kept everyone motivated to learn and actively participate in the day's learning activities. Weekly activities allowed participants with diverse interests to have something to look forward to with cultural activities as the driver for some and weekly gym days the driver for others.

Space. Building cohesion within the cohort was essential for the camp's success. Creating a community that was invested in the success of each its members helped to develop a caring and respectful environment in which students wanted to come and learn. This was accomplished by sharing meals together. Creating a communal atmosphere where everyone was included, enjoying themselves, and sharing stories about their day fostered a sense of belonging. In other words, having a welcoming space where the camp participants would feel comfortable was one of the key components of our concept.

On the practical side, the camp required two classrooms for mathematics and English instruction, a kitchen facility 
Table 4. Typical weekly schedule. ${ }^{*}$ For the math and English classes, camp participants were split in two groups, based on the level of their math knowledge.

\begin{tabular}{|c|c|c|c|c|}
\hline \multicolumn{5}{|c|}{ Academic Summer Camp for Aboriginal Students - Weekly Schedule } \\
\hline Monday & Tuesday & Wednesday & Thursday & Friday \\
\hline Breakfast & Breakfast & Breakfast & Breakfast & Breakfast \\
\hline Math/English & Math/English & Math/English & Math/English & Math/English \\
\hline English/Math* & English/Math & English/Math & English/Math & English/Math \\
\hline Lunch & Lunch & Lunch & Lunch & Lunch \\
\hline Science Activities & Recreational Activities & Applied Science Activities & Cultural Activities & Special Events \\
\hline
\end{tabular}

for food preparation and service, a space to share meals, office space for the Camp Coordinator, and storage space. Another space, flexible in the sense that the furniture could be easily rearranged, was needed for the afternoon workshops when the whole group was working together.

Coordinating the facilities for the first three years was easily handled through the IRMACS Centre. The first-class facility provided the camp organizers and participants with everything that they needed: excellently equipped classrooms, theatre, kitchen, and lounge space. Still, the most important contribution that the IRMACS Centre made to the camp was the welcoming and supportive attitude presented from day one in all interactions between the camp participants and staff and the members of the IRMACS community. There was no doubt in anyone's mind that the IRMACS Centre was the true home for all camp participants during their stay at SFU. When the IRMACS Centre closed in 2016, coordinating and securing the appropriate space for the camp became a major challenge.

\section{CONCLUSION}

The camp was an attempt to address the complex issue of underrepresentation of Indigenous students at post-secondary institutions (Gallop and Bastien, 2016). This attempt was based on the belief that universities should take a proactive role and reach out to Indigenous high school students even if they still have a couple (or a few) years to graduation.

The model promotes outreach at multiple levels:

- Academic level: Supporting students in their academic growth, particularly in mathematics and English, the two major requirements for the university enrollment

- Cultural level: Supporting students in their growth as members of the Indigenous community, particularly high school students in urban areas

- Social level: Supporting students in their growth as young people by providing them with the opportunities to meet new friends and learn about and become engaged in social activities

- Intellectual level: Exposing students to the ideas and activities in science and art that otherwise they may not experience
- Practical level: Providing additional opportunities to students to apply and further develop some of the skills, such as public speaking or learning strategies, that are necessary for communicating existing and gaining new knowledge.

- Personal level: Providing additional opportunities to students to explore their academic and other interests and talents, eat healthy, earn money, and in general take responsibility for their actions

As described by Pidgeon et al. (2014), one can find a set of similar ideas related to the education of Indigenous learners at the graduate level. Among the most surprising experiences that the camp organizers had was the realization that in the addition to the need to create the environment in which the camp participants would "maintain their own cultural integrity" (Pidgeon, 2009) they also faced the challenge to help the members of the urban Indigenous youth to discover or re-discover their connections with their cultures.

When I think back to the camp last summer, besides the unforgettable experiences at TRIUMPH and the cool forensics day... I remember making new and lasting friends! I was with kids I had never met before, yet we all had one thing in common; we're aboriginal. Being surrounded by my fellow youth in an unfamiliar environment changed my perspective of university. We had the freedom to explore SFU together and it became less intimidating as the month progressed. I feel like college/university is now a realistic place for me to be, after high school. Since last July, I went to Lillooet, BC where I visited my band for the first time (Ts'qw'aylaxw First Nation) with my dad and uncle. -

\section{Camp participant}

Here is a related question that we heard from our colleagues: "Is it in the university's mandate to help high school or mature students to upgrade their academics so that they meet the university requirements for enrollment?" Our answer to the question above is a resounding yes. If nothing else universities should start investing in recruiting Indigenous learners early because for a straightforward reason: by not doing so, our post-secondary institutions are missing out on a pool of exceptional talent and potential. The aca- 
demic path of the second author of this note supports this point: she enrolled in the university as a mature student after completing a year-long SFU Aboriginal University Preparation Program and graduated with honors while co-authoring three research papers as an undergraduate student. Currently she is a master's student and an instructor in the Aboriginal University Preparation Program.

At the same time, it is unreasonable to expect Canadian universities to create stable core funding for outreach and recruiting activities targeting Indigenous youth, such as the camp. Despite their possible successes, these types of activities will continue to be funded by "soft" money, i.e., by donations, grants, and other short-term commitments. Building, developing, and running programs with their expiration date looming creates a sense of instability for all participants. It also creates a sense of loss when the committed funds are eventually exhausted.

The uneasy dynamics between the necessity of strong outreach and recruiting activities focusing on Indigenous learners and the reality of short-term institutional commitments for individual programs makes the role of champions, individuals and communities, of those programs even more important. Programs such as this one run thanks to the commitment of the individuals who are willing to, despite all obstacles, apply their knowledge, beliefs, skills, and talents for the benefit of the Indigenous learners, their communities, and Canadian society at large.

But what is it that a program like the Academic Summer Camp can realistically achieve? It can help one young person at a time learn more about themselves and the world around them and encourage them to pursue a post-secondary education.

The SFU camp was a real turning point for me. Prior to camp I lacked self-confidence and did not have a real understanding of my culture. By the end of the month I really started believing in myself. I was also excited to learn more about my culture. The teachers were inspiring, and the other students were amazing. I miss them. I have kept in touch with some and built some lifelong relationships. This past year I have been involved in many different things that I am not sure I would have been able to have I not developed more self-confidence through the SFU camp. Thank you to you, and everyone involved in the SFU camp for making a huge impact on me and my future. - Camp participant

\section{AUTHOR INFORMATION Corresponding Author \\ Veselin Jungic.vjungic@sfu.ca.}

\section{Author Contributions}

The manuscript was written through contributions of all authors, who have given approval to the final version of the manuscript.

\section{ACKNOWLEDGMENTS}

We would like to thank Dr. Ozren Jungic and Ms. Pam Borghardt for their contribution to improving the text. The photo accompanying this article on the website was provided courtesy of The Math Catcher Outreach Program.

\section{ABBREVIATIONS}

FNMI: First Nations, Metis, and Inuit; NSERC: Natural Sciences and Engineering Research Council of Canada; OAP: Office for Aboriginal Peoples; PIMS: Pacific Institute for Mathematical Sciences; SFU: Simon Fraser University; UBC: University of British Columbia.

\section{REFERENCES}

Alvarez, M. (2019). Addressing mathematical inequity in indigenous education: Efforts by mathematicians and Educators in Western Canada. Notices of the American Mathematical Society, 66(4), 534-539.

Archibald, T., and Jungic, V. (2016). Mathematics and First Nations in Western Canada: From cultural destruction to a re-Awakening of mathematical reflections, In B. Larvor (Ed.), Mathematical Cultures, The London Meetings 2012-2014 (pp. 305-328). Basel, Switzerland: Springer.

Fractal Foundation. (2020). https://fractalfoundation.org/resources/what-are-fractals/, Accessed April 11, 2020.

Frawley J., Larkin S., and Smith J. (eds) (2017). Indigenous Pathways, Transitions and Participation in Higher Education. Springer, Singapore.

Gallop, C. J., and Bastien, N. (2016). Supporting success: Aboriginal students in higher education. Canadian Journal of Higher Education, 46(2), 206-224.

Hogue, M.M. (2016). Aboriginal ways of knowing and learning, 21 st century learners, and STEM success. in education, 22(1), 161-172.

Institutional Research and Planning. (2020a). https://www.sfu.ca/ irp. https://www.sfu.ca/irpl. Accessed April 11, 2020.

Institutional Research and Planning. (2020b). https://www.sfu.ca/ irp/students.html\#headcounts. Accessed April 11, 2020.

Klein, B., and Shubin, T. (2019). Building the Alliance of Indigenous Math Circles. Notices of the American Mathematical Society, 66(4), 540-546.

Math Catcher Outreach Program. (2020a). http://www.sfu.ca/ mathcatcher.html. Accessed April 11, 2020. 
Math Catcher Outreach Program. (2020b). Camp Participant Expectation Agreement. Retrieved April 11, 2020, from http://www.sfu.ca/content/dam/sfu/mathcatcher/MathCamp/2017Camp/Math\%20Camp\%20Participant\%20Expectation \%20Agreement.pdf.

Ottmann J. (2017). Canada's indigenous peoples' access to post-secondary education: The spirit of the 'new buffalo'. In: J. Frawley, S. Larkin, and J. Smith (Eds), Indigenous Pathways, Transitions and Participation in Higher Education. Springer, Singapore.

Pacific Institute for the Mathematical Sciences (PIMS). (2020). Emerging Aboriginal Scholars summer camp. https:// www.pims.math.ca/educational-event/110705-eassc. Accessed April 11, 2020.

Phillips, C., and Ly, F.-K. (2020). Mathematics education for Indigenous students in preparation for engineering and information technology: Cultural plasticity for Indigenous mathematics. In D. H. Bailey, N. Borwein, R. P. Brent, R. S. Burachik, J.-A Osborn, B. Sims, and Q. Zhu (Eds.), From analysis to visualization: A celebration of the life and legacy of Jonathan M. Borwein, Callaghan, Australia, September 2017 (pp. 153-169). Springer.

Pidgeon, M. (2009). Pushing against the margins: Indigenous theorizing of "success" and retention in higher education. Journal of College Student Retention: Research, Theory and Practice, 10(3), 339-360.

Pidgeon, M., Archibald, J., and Hawkey, C. (2014). Relationships matter: Supporting Aboriginal graduate students in British Columbia, Canada. Canadian Journal of Higher Education, 44(1), 1-21.

Reconciliation at SFU. (2020). https://www.sfu.ca/reconciliation. html. Accessed April 11, 2020.

Statistics Canada. (2017). Education in Canada: Key results from the 2016 Census. Retrieved April 11, 2020, from https://www150.statcan.gc.ca/n1/daily-quotidien/171129/ dq171129a-eng.htm.

Theodore, R., Tustin, K., Kiro, C., Gollop, M., Taumoepeau, M., Taylor, N., Chee, K., Hunter, J., and Poulton, R. (2016) Māori university graduates: indigenous participation in higher education, Higher Education Research and Development, 35:3, 604-618, DOI: 10.1080/07294360.2015.1107883.

Truth and Reconciliation Commission of Canada. (2015). Canada's Residential Schools: The Legacy: The Final Report of the Truth and Reconciliation Commission of Canada, Volume 5. McGill-Queen's University Press. Retrieved March 15, 2020, from www.jstor.org/stable/j.ctt19rmbqj.

University of Canterbury. (2020). He Puna Pūtaiao. https:// www.canterbury.ac.nz/science/outreach/events/he-punaputaiao/f. Accessed April 11, 2020. 